\title{
Virtual Training in Safety and Security - TUAS Visions for Next Generation Learning
}

\author{
Mika Luimula ${ }^{1}$, Roosa Talvitie ${ }^{1}$, Nina Rantalaiho-Kulo ${ }^{2}$ \\ ${ }^{1}$ Turku University of Applied Sciences, Finland. ${ }^{2}$ Mazin Al-Adawi, Nizwa College of \\ Applied Sciences, Oman
}

\begin{abstract}
The new suggested collaboration is related to the development of learning materials for a virtual environment that can be used in multi-professional exercises for improving safety and security in bodies of water and /or in urban settings. We have identified both national and international needs for virtual training. In particular, safety and security linked to dangerous or hazardous working environments seems to be one of the first domains where virtual training should be widely applied. We are searching for both end-users (such as shipping companies or fire departments) but also researchers from various fields. In order to be able to develop new, innovative learning contents we will need to establish a multidisciplinary team which is able to design and implement suitable educational concepts but which is also able to measure the impact in improved safety and security conditions. In this paper we will use a virtual fire safety training application as an example of a next generation learning tool and method. Finally, we will show our first field experiences from Oman..
\end{abstract}

Keywords: Maritime Safety, Urban Safety, Virtual Reality, Next Generation Learning, Emergency Services 


\section{Background of the topic}

TUAS has participated in various safety and security related projects recently in which needs for virtual training has been identified. TUAS was involved 2018-2019 in a bilateral, FinnishRomanian capacity building project that was focused on developing and implementing an emergency- operator training programme in Romania. This joint venture, implemented in cooperation with the Romanian Centre for Health Policies Services, was supported both by the Finnish and Romanian Ministries of the Interior. The main outcomes of the project were, in addition to the strengthening of the infrastructure of two simulator-focused dispatcher training centres, a comprehensive curriculum for the dispatcher training programme, stateof- the-art training materials and a strategy for implementing and scaling up of the training programme in Romania.

OnBoard Med - Harmonization of onboard Medical treatment, Occupational Safety and Emergency skills in Baltic Sea Region (Central Baltic 2016-2019) aimed at developing more aligned vocational education programmes in the Central Baltic area. The project has developed 9 courses (varies 2-8 ECTS) in maritime emergency management, medical treatment and occupational safety. The courses are suitable at maritime (seamen, deck officer, maritime engineer) and nursing institution (Nurse, emergency care nurse and public health nurse). The one main idea in this project was the close co-operation between maritime and nursing institutions. Mariners and ship nurses are together a team onboard. They have to cooperate fluently and effectively onboard in emergency care situation. You will found different kind of learning material from contact lessons to videolessons, different tasks, ideas for workshops, and specific description of the simulation scenarios.

Business Finland funded Allied ICT Finland (AIF) is a collaboration network of Finnish ICT research institutes and their cities, national ecosystems both applying and enabling ICT, thousands of researchers and more than 1200 companies. Digitalization creates vast possibilities for growth, but new ways of agility, investments and partnership models are needed in order to succeed. Finland must be in the vanguard of new technologies and business opportunities. Allied ICT Finland offers a new model of action and investment, which aims to create a billion euro R\&D leap. TUAS School of ICT has been participating in this project since 2018. One of the research focus areas has been in virtual safety training (and virtual training centers). TUAS is investing in 2019-2021 around 0.5M€ for AR and VR technologies. This investment enables to establish first virtual training centers with TUAS industrial partners.

It is forecasted that in 2050, two-thirds of the world`s population will live in cities and urban areas (United Nations, 2018). Due to the growing environmental concerns, instead of using airplanes, citizens will increasingly be travelling by alternative modes boat or by train. Europe has many big lakes and long rivers that will be facing a growing use of passenger 
ships. The development of comprehensive safety and security systems will thus be crucial in the bodies of water (sea, river and lake areas).

Based on the experiences gained from the two ambitious international research and capacity building - focused collaborations that TUAS has been partnering in, it has become evident that the use of state-of-the- art simulation and e-learning techniques, combined with the use of AR and VR technologies, can provide outstanding solutions in education and training in the field of safety and security. The added value of the recourse to these technologies is in particular (but not limited to) the possibilities of simulating situations in challenging environments which might otherwise not be physically feasible (eg maritime safety situations), as well as the possibility of enabling the multiplication of these trainings to a large number of trainees with limited/reasonable costs/resource-efficiency. TUAS is setting up an virtual training centers focused on the thematics of safety and security, and has a longstanding experience in cooperating with international and national maritime safety authorities, research institutions as well as relevant industry partners.

\section{Problem statement or concrete goals or steps}

TUAS has piloted virtual training with various industrial partners. Typical users in industry have few or no gaming experiences. That's why our partners have been especially interested in fresh solutions which could improve usability, user experience, and user interface design. In this paper, we shortly introduce some of our virtual training applications. In addition, we will focus on a fire safety application which have been tested in Finland but now also in Oman. This case study shows the potential of setting up an international consortium to focus on safety and security training in virtual environments. A project in which we will focus on hands-on-training solution in demanding and hazardous training should standardize virtual training and form basis for new business ecosystem of next generation learning environments.

\section{Some details and specifics on the basis for the future project}

Currently we have three key pilot projects in marine industry (Figure 1). The first is a maintenance training solution to assist engineers in the engine room, while the second is a gamified crane training for crane drivers, and the third one is a virtual command bridge simulator (Markopoulos et al., 2019). 

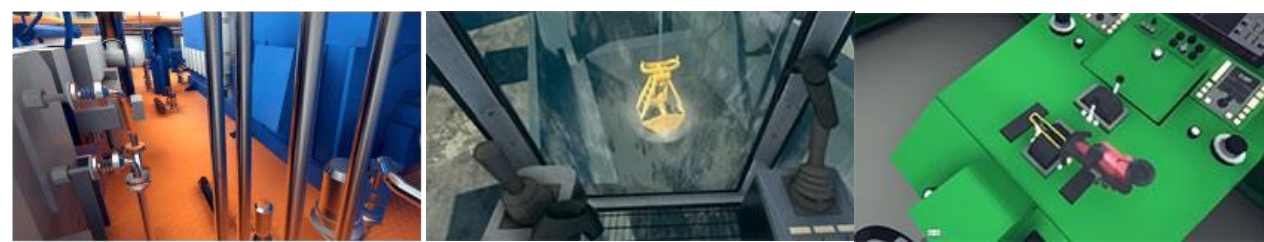

Figure 1. Three VR training solutions for marine industry.

Before focusing on marine industry we have studied virtual reality in driving inspection (Luimula et al., 2015; Hämäläinen et al., 2017). As a result we created NeuroCar evaluation tool for a simultaneous evaluation of driving acuity and spatial perceptual capacity. In addition, we have developed training solutions for drivers.
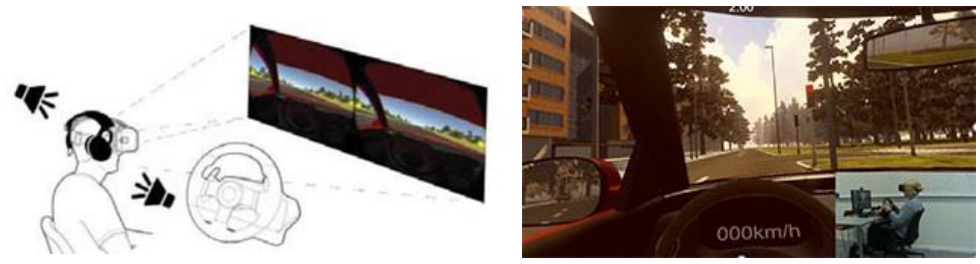

Figure 2. System description of the NeuroCar evaluation tool and street view from the NeoroCar training solution.

In this paper, we will focus more on virtual fire safety training which is a part of both marine and urban safety. Our largest safety training field experiment so far has consisted of 169 test subjects (Oliva et al., 2019). In this study, player's task was to escape the building on fire. We showed that this virtual training solution called Virpa is a suitable tool for communication relating to fire safety.

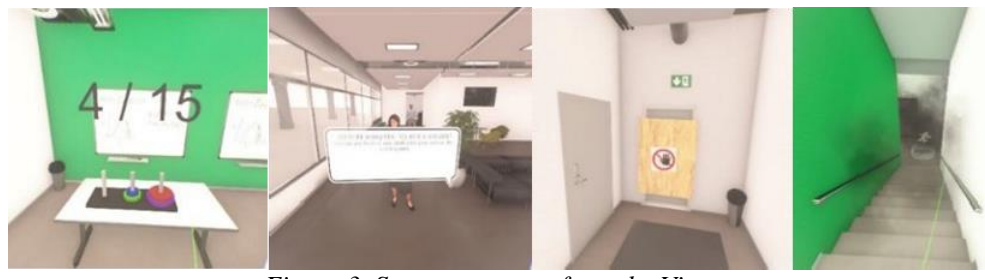

Figure 3. Screen captures from the Virpa game.

As a continuum for Virpa (Figure 3) we have developed a fire safety to learn how to use fire extinguishers. The main object in this fire safety training solution (Figure 4) is to develop the player's initial fire safety skills. The manuscript of this learning episode is as follows: "The environment is a simple room with a metal cabinet. The player comes in and sees the electric cabinet on fire. He or she should choose the most appropriate extinguishing method for the situation. The options include a fire blanket, a membrane foam fire extinguisher, a fire hose, and a $\mathrm{C} 02$ fire extinguisher. The player should be able to choose a $\mathrm{C} 02$ fire extinguisher 
designed for electrical, gas and oil burns. The fire is initially inside the electrical cabinet and only smoke is visible to the hallway where the player is. Later, a larger flame will also appear.

Figure 4. The application is monitoring player's behavior and the feedback is shown at the end of the training.

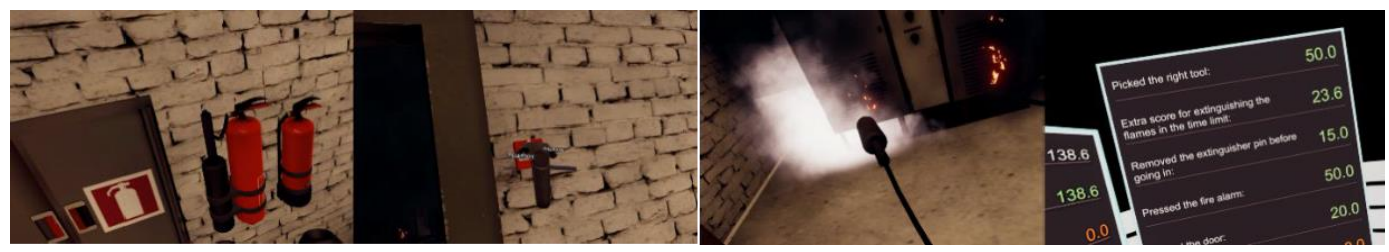

After selecting the $\mathrm{C} 02$ fire extinguisher, releasing the pin and opening the door, the smoke floats in the air and also player's face gets smoke. The player has to approach the burning object in the pile and stay on his knees during the shutdown. The player should be able to point the nozzle to the root of the flames and the trigger handle must be able to be pressed. Our training solution is tracking and tracing the player's behavior during the game. The player should be able to pick up the correct tool. Extra score will be given if extinguishing the flames in the time limit. The player should remove the pin before going in. In addition, the player should press the fire alarm, and close the door at the end. The player will be given penalty score for standing in the smoke or if going too close to the fire. All this feedback is visualized for the player at the end of the learning episode. If needed the player is able to start all over again to make enough repetitions for the correct actions. The duration of this learning episode is around 10 minutes and application contains minimal textual information which can be translated easily for different nationalities.

This application is developed in Finland and has received promising feedback from the technology industry. Therefore we decided to test this application in a different cultural context in Oman. The application has been tested with 16 trainees in National Training Center (NTI) in Muscat. The preliminary results (Figure 5) in this small scale experiment below shows that we received quite promising results. Trainees felt that they were able to learn, and understand fire safety issues. In addition, it seems that they would prefer to use virtual rather than traditional training methods.

Figure 5. Results of the user experience and user satisfaction questionnaire.

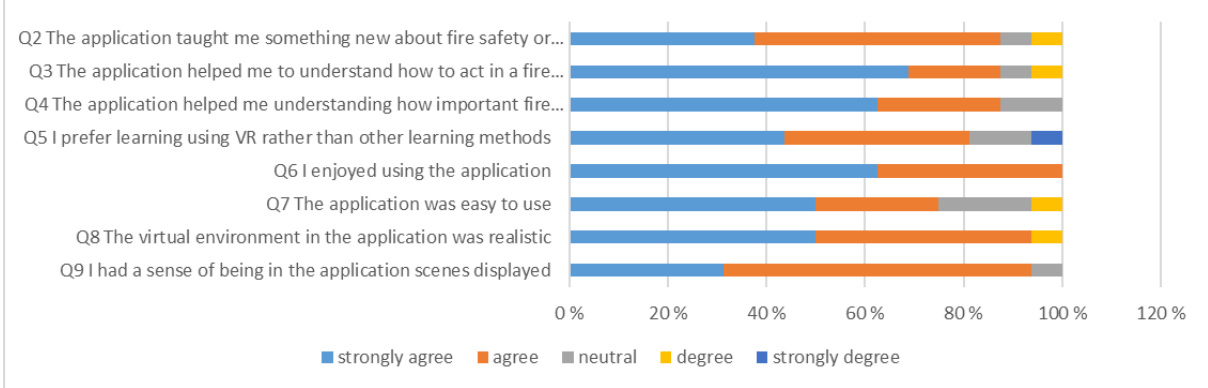




\section{References}

United Nations (2018) 68\% of the world population projected to live in urban areas by 2050, says UN", DOI = https://www.un.org/development/desa/en/news/population/2018revision-of-world-urbanization- prospects.html

Markopoulos, E., Lauronen, J., Luimula, M., Lehto, P., and Laukkanen, S. (2019) Maritime Safety Education with VR Technology (MarSEVR), In: Proceedings of the 9th IEEE Conference on Cognitive Infocommunications (accepted)

Luimula, M., Besz, A., Pitkäkangas, P., Suominen, T., Smed, J., Izullah, F.R., and Hämäläinen, H. (2015) Virtual Evaluation Tool in Driving Inspection and Training, In: Proceedings of the 5th IEEE Conference on Cognitive Infocommunications, Gyor, Hungary, pp. 57-60.

Hämäläinen, H., Izullah, F.R., Koivisto, M., Takio, F., and Luimula, M. (2018) The Rightside Perceptual Bias in Aging Determined in a Laboratory and during a Virtual Driving Task, Scandinavian Journal of Psychology, Vol. 59, pp. 32-40.

Oliva, D., Somerkoski, B., Tarkkanen, K., Lehto, A., and Luimula, M. (2019) Virtual Reality as a Communication Tool for Fire Safety - Experiences from the VirPa Project, In: Proceeding of the $2^{\text {nd }}$ Gamifin Conference, Levi, Finland, pp. 241-252. 